\title{
Evaluation and assessment of Knowledge, Attitude and Practice of Pharmacy students towards Pharmacovigilance in Saudi Arabia: A Cross sectional study.
}

\author{
Ayesha Siddiqua ( $\sim$ aishaa2804@gmail.com ) \\ King Khalid University https://orcid.org/0000-0001-9882-7695 \\ Nada Alshahrani \\ King Khalid University \\ Javid Mir lqbal \\ King Khalid University \\ Afnan Mohammad Ali \\ King Khalid University \\ Raghad Abdulrahman \\ King Khalid University \\ Salha ahmad alqarni \\ King Khalid University \\ Amjad almanaa \\ King Khalid University \\ Waad ahmad asiri \\ King Khalid University \\ Mohammed A Al Essa \\ King Saud bin Abdulaziz University for Health Sciences \\ Jawaher Abdullah Gramish \\ King Abdulaziz Medical City \\ Moteb A Khobrani \\ King Khalid University
}

Research article

Keywords: Pharmacovigilance, Knowledge, Attitude, Practice, Pharmacy students

Posted Date: August 22nd, 2019

DOI: https://doi.org/10.21203/rs.2.13367/v1 
License: (c) (i) This work is licensed under a Creative Commons Attribution 4.0 International License. Read Full License 


\section{Abstract}

BACKGROUND: Pharmacovigilance is an important part of the health care system as it helps in the detection, assessment, reporting and prevention of Adverse Drug Reactions. Spontaneous reporting of adverse drug reaction plays a vital role in the success of Pharmacovigilance programs and pharmacy students are supposed to acquire sufficient knowledge and necessary skills required for practicing pharmacovigilance under different clinical settings. Hence, this study was carried out in the students of College of Pharmacy of a University in the Southern Province of Saudi Arabia to assess the Knowledge, Attitude and Practice (KAP) of undergraduate Pharmacy students towards Pharmacovigilance. METHODS: A quantitative, prospective, cross-sectional online survey was carried out using a validated, self-administered questionnaire constituting 4 domains i.e. Demographics, Knowledge, Attitude and Practice of Pharmacovigilance among the pharmacy students of King Khalid University. RESULTS: The questionnaire was administered to 360 students out of which 329 responded (response rate of $91.3 \%$ ). The mean score of Level 7,8,9,10 and intern students for Knowledge was $(3.03,5.37,6.38,6.19,6.42)$, Attitude $(5.28,4.16,5.62,5.01,5.29)$, and Practice $(2.99,3.25,3.04,3.43,3.13)$ respectively. In addition, the findings indicated a significant difference in the mean score among different level of students for knowledge and attitude with a $p$-value of $<0.0001$, and 0.0002 respectively. The practice mean score showed there was no much significance among different level of students ( $p$-value $=0.4108$ ) CONCLUSION: Our research findings revealed that the pharmacy students of the focused university have adequate knowledge and positive attitude towards adverse drug reaction. However, there is a dire need to understand and address concerns regarding real time practice patterns prevalent among Health Care Providers about pharmacovigilance under different clinical settings. Keywords: Pharmacovigilance, Knowledge, Attitude, Practice, Pharmacy students

\section{Background}

Pharmacovigilance is an important part of the health care system as it helps in the detection, assessment, understanding and prevention of adverse drug reactions. It maintains the safety of the marketed medicines and primarily focusses on the adverse drug reactions and patient care. It also tries to heed on building healthy collaboration at different national and international levels, to deliver its complete benefits ("P V Chronicle - PV Jobs \& Updates", 2018). At International level, World Health Organization (WHO) has an alliance with the Centre for International Drug Monitoring, Uppsala, to promote Pharmacovigilance whereas in Saudi Arabia the National Pharmacovigilance and drug safety center has been established under the charge of Saudi Food and Drug Authority which is responsible to promote Pharmacovigilance (Alshammari, Alshakka, Aljadhey, 2017). Adverse event reporting is a requisite for all the clinical research investigators, even if the side effects are only suspected. In other words, analyzing which side effects are worth the risk to patients compared with how effective they are at treating a disease. Spontaneous reporting of adverse drug reaction plays a prominent role in the success of Pharmacovigilance program (Muraraiah et al., 2011). 
As Pharmacovigilance is a subject of broad and current interest, significant studies have been carried out on this context globally Suyagh et al., 2015, Alsaleh et al., 2017, Gupta et al., 2017 but limited studies have been carried out in this required domain in Saudi Arabia. So our aim was to widen it out and conduct a survey among the pharmacy students who are the future health care providers and being a pharmacy student they are supposed to acquire sufficient knowledge and necessary skills required for practicing pharmacovigilance under different clinical settings. This could result in an improvement in the Adverse drug reaction reporting in the future which will in turn reduce the health-care expenditures and costs associated with an adverse drug reaction and its treatment that goes beyond reach.

\section{Aim Of The Study}

This study was carried out in the students of College of Pharmacy of a University in the Southern Province of Saudi Arabia to assess the Knowledge, Attitude and Practice (KAP) of undergraduate Pharmacy students towards Pharmacovigilance.

\section{Methods}

Study design and setting: This prospective, cross-sectional descriptive online study was designed to assess the level of knowledge, attitudes and practices of Pharmacovigilance among the undergraduate students of College of Pharmacy, King Khalid University, Abha, Saudi Arabia.

Target population, Sampling Criteria and Sample size: The College of pharmacy of this university has a large group of students both male and female distributed in each level from Level-1 to Level-10. Each academic year comprises of 2 levels with a total of 5 years. Each level refers to a single semester of study. Later on they are subjected to a training period of one year in primary health care centers, and Pharmacies which is known as internship. This web-based survey was carried out on a sample of study participants constituting both male and female students who belonged to the fourth, fifth year students (Level-7,8,9,10) and those undergoing their internship during the study period (October 2018-November 2018). We excluded the students below Level- 7 and the students who do not belong to the Pharmacy College.

We used a simple random sampling technique and our estimated sample size was 359 calculated by Raosoft method with a confidence interval of $99 \%$. The online questionnaire link was given to the student leader of each level and they further forwarded the link to the students through their WhatsApp groups.

Survey instrument development and Data collection: Furthermore, a self-administered structured prevalidated questionnaire based on previous similar studies (Gupta, Sharma, Malhotra, 2017) was adapted. The questionnaire was then subjected to a review and validation process by experts from the members of the research team to ensure that the survey was sufficiently comprehensive and suitable to our study. A pilot study was then carried out to determine the validity, reliability and clarity of the questionnaire. The feedback was analyzed and a finalized questionnaire was developed accordingly. 
The questionnaire constituted of 4 domains. The first section included the independent variables of the study i.e. details of participants like gender and level of education. The second section constituted of 11 closed-ended questions in a multiple choice format that intended to assess the Knowledge of students towards Pharmacovigilance. The third section constituted of 7 questions in Yes/No format to assess their attitude towards Pharmacovigilance, whereas the last section i.e. the fourth section included 6 questions pertaining to the practice of Pharmacovigilance in Yes/No format. The dependent variables of this study were Knowledge, Attitude, and Practice. The questionnaire was converted into a web-based format and was delivered to the study participants, with the data being collected from October to November 2018. Eligible participants were approached.

Statistical Analysis: The results were downloaded and stored in Microsoft excel spreadsheets. Data were analyzed using SPSS version 21.0 statistical software (IBM Inc., Chicago USA). Descriptive statistics (mean and standard deviation) were used to describe the categorical study and outcome variables. Unpaired student's t test, One way analysis of Variance and Bonferroni multiple comparison test were used to compare the mean score of the domains i.e Knowledge, Attitude and Practice between different gender and levels of students. A p-value of $\leq 0.05$ and $95 \%$ confidence intervals was used to report the statistical significance and precision of results in the tables.

\section{Results}

The online questionnaire constituting 3 dependent variables Knowledge, Attitude, Practice with a total score of 11, 7, and 6 respectively was self-administered to 359 participants, out of which 329 responded giving a response rate of $91.3 \%$. Seventy-seven percent $(n=254)$ of the students were based on the female campus, while the remaining $23 \%(n=75)$ were based on the male campus.

Gender wise comparison of mean scores for Knowledge, Attitude and Practice questions:

The mean scores of the participant's knowledge was calculated which has been shown in Table-1. Unpaired student's t-test was carried out to compare the knowledge of the participants across different genders and it was estimated that the mean score of female participants was found to be $6.2+2.1$, whereas for the males it was $5.79+2.25$ with an estimated two tailed $p$ value of $0.1374(<0.05)$ which stated that the means were not significantly different.

Furthermore, Table- 1 also shows the mean score of the participants towards attitude-based questions across different genders. Unpaired student's t-test was carried out to compare the attitude of the participants across different genders and it was estimated that the mean score of female participants was $5.22+1.78$, whereas for the males it was $4.64+1.8$ with an estimated two tailed $p$ value of 0.0131 $(<0.05)$ with a significant difference.

The students were also posed some basic questions which assessed their practice towards pharmacovigilance which has also been summarized in Table-1. Unpaired t-test was carried out to compare the practice of the participants across different genders and it was estimated that the mean 
score of female participants was $3.21+1.47$, whereas for the males it was $3.03+1.47$ with an estimated two tailed $p$ value of $0.3459(<0.05)$ with no significant difference.

The mean score of knowledge of the participants were estimated and compared across different levels of both the genders. The mean score for Level- 7,8,9,10 and the intern students was found to be $3.03+1.47$, $5.37+2.14,6.38+2.21,6.19+2.03,6.42+2.31$ respectively. A one-way analysis of variance was carried out and the estimated $p$ value was $<0.0001(<0.05)$ which showed there was a significant difference. $A$ Bartlett's test for equal variances was also carried out with a p value of $0.0026(<0.05)$ which states that there was a significant difference between the groups. A bonferroni's multiple comparison test was also carried out across the different levels to know which group is more significant which has been clearly displayed in Table-2.

The mean score of the attitude of the participants were estimated and compared across different levels of both the genders. The mean score for Level-7,8,9,10 and the intern students was found to be $5.28+1.82,4.16+1.93,5.62+1.56,5.01+1.62,5.29+1.76$ respectively. A one-way analysis of variance was carried out and the estimated $p$ value was $0.0002(<0.05)$ which showed there was a significant difference. A Bartlett's test for equal variances was also carried out with a p value of $0.4716(<0.05)$ which states that there was no significant difference between the groups. A bonferroni's multiple comparison test was also carried out across the groups and the details have been summarized in Table3.

The mean score of the practice of the participants were estimated and compared across different levels of both the genders. The mean score for Level-7,8,9,10 and the intern students was found to be $2.99+1.53,3.25+1.54,3.04+1.56,3.43+1.29,3.13+1.42$ respectively. A one-way analysis of variance was carried out and the estimated $p$ value was $0.4108(<0.05)$ which showed there was no significant difference. A Bartlett's test for equal variances was also carried out with a p value of $0.5233(<0.05)$ which states that there was no significant difference between the groups. A bonferroni's multiple comparison test was also carried out across the groups and the details have been summarized in Table4.

\section{Discussion}

From the findings of this study it was clear that the students of this university have adequate knowledge and positive attitude towards Pharmacovigilance which corroborates with the findings of (Abdel-Latif, Abdel-Wahab, 2015). In the findings of Abdel-Latif and Abdel-Wahab, 2015, the respondents were unable to correctly define the Pharmacovigilance term, but they were aware of ADRs whereas in our findings we could see that many students were able to define the term Pharmacovigilance correctly as well as they were very much aware about Adverse drug reactions and their reporting systems but most of them were not aware of the system followed in Saudi Arabia for reporting an Adverse drug reaction and also most of them had not seen the form used in Saudi Arabia. In a previous study conducted by Othman and colleagues among the Pharmacy students (Othman et al., 2017), most of their respondents had a poor 
knowledge on this concept which differs from the results of our university. There was another study conducted in Saudi Arabia in Dammam by Ali and his colleagues in which their respondents also had inadequate knowledge and poor attitude which differs from our results (Ali et al., 2018). This difference in the findings of knowledge and attitude among different studies may be due to the differences in the teaching curriculum as well as the level of training received. Whereas regarding the practice of Pharmacovigilance, our study findings showed that the students required enough training to improve their skills. Many studies conducted previously among the student groups as well as those conducted among health care professionals by Suyagh et al., 2015, Alsaleh et al., 2017, Gupta et al., 2017 stated that their study participants also had a poor practice which is in accordance with our findings.

Vora et al., 2012, suggested that initiation of organized training programmes regarding Pharmacovigilance in undergraduate medical curriculum has to be mandatory if we wish to see better results in the future as these students are future prescribers in the society and also they suggested to provide an online and telephone line accesses to facilitate adverse drug reactions reporting system. This also implies to the students of our study because Pharmacy students are also future health care providers. So, conducting workshops in future to create awareness among them could be beneficial.

Limitations: This study is not without its limitations. The participants might have easily got the answers to the questions from their fellow-mates or through online access as we used a self-administered webbased questionnaire which could have affected the accuracy of our findings, particularly in the knowledge section, because this method does not allow us to have a look at the behavior of the participant while they complete the survey.

\section{Conclusion}

Our research findings revealed that the Pharmacy students of this university have adequate knowledge and positive attitude towards adverse drug reaction reporting, however there is a dire need to understand and address concerns regarding real time practice patterns prevalent among Health Care Providers about Pharmacovigilance under different clinical settings. Educational intervention programs, like incorporation of this concept in undergraduate practical, Continuous medical education (CME), conducting workshop on pharmacovigilance may help in improving adverse drug reaction (ADR) monitoring and reporting skills.

\section{Declarations}

\section{ETHICS APPROVAL AND CONSENT TO PARTICIPATE:}

The study was approved by the Ethics Committee of College of Pharmacy, King Khalid University and all the respondents were asked for their verbal consent before participation in the study. Assessment of the responses was done blindly. 


\section{CONSENT FOR PUBLICATION:}

Not applicable

\section{AVAILABILITY OF DATA AND MATERIALS:}

The data sets used during the current study are available from the corresponding author on reasonable request.

\section{COMPETING INTERESTS:}

The authors declare that they have no competing interests.

\section{FUNDING:}

The authors declare that they have not received any funding.

\section{AUTHORS' CONTRIBUTIONS:}

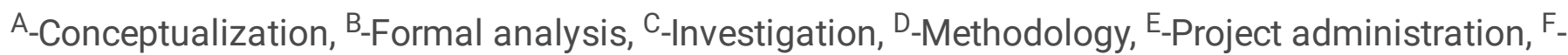
Resources, ${ }^{G}$-Supervision, ${ }^{\mathrm{H}}$-Validation, '-Visualization, ${ }^{J}$-Writing-original draft, ${ }^{\mathrm{K}}$-Writing-review \& editing.

Ayesha Siddiqua A-K, *, Nada H Alshahrani A, C-E, Mir Javid Iqbal ${ }^{\mathrm{F}-\mathrm{I}, \mathrm{K}}$, Afnan mohammad ali $\mathrm{C}-\mathrm{E}, \mathrm{J}$, Raghad Abdulrahman ${ }^{\mathrm{C}-\mathrm{E}, \mathrm{J}}$, Salha ahmad alqarni ${ }^{\mathrm{C}-\mathrm{E}, \mathrm{J}}$, Amjad almanaa ${ }^{\mathrm{C}-\mathrm{E}, \mathrm{J}}$, Waad ahmad asiri ${ }^{\mathrm{C}-\mathrm{E}, \mathrm{J}}$, Mohammed Al Essa ${ }^{\mathrm{K}}$, Jawaher Gramish ${ }^{\mathrm{K}}$, Moteb Khobrani ${ }^{\mathrm{K}}$

\section{ACKNOWLEDGEMENTS:}

The authors would like to thank the students of this University to participate in this survey and the members of the research committee to guide us throughout our study.

\section{References}

Abdel-Latif M, Abdel-Wahab B. Knowledge and awareness of adverse drug reactions and pharmacovigilance practices among healthcare professionals in Al-Madinah Al-Munawwarah, Kingdom of Saudi Arabia. Saudi Pharm J. 2015;23(2):154-61.

Ali M, Hassan Y, Ahmed A, Alaqel O, Al-Harbi H, Al-Suhaimi N. Knowledge, Practice and Attitudes Toward Pharmacovigilance and Adverse Drug Reactions Reporting Process Among Health Care Providers in Dammam, Saudi Arabia. Curr Drug Saf. 2018;13(1):21-25. 
Alsaleh F, Alzaid S, Abahussain E, Bayoud T, Lemay J. Knowledge, attitude and practices of pharmacovigilance and adverse drug reaction reporting among pharmacists working in secondary and tertiary governmental hospitals in Kuwait. Saudi Pharm J. 2017; 25(6): 830-837.

Alshammari T, Alshakka M, Aljadhey H. Pharmacovigilance system in Saudi Arabia. Saudi Pharm J. 2017; 25(3): 299-305.

Gupta R, Sharma D, Malhotra P. Assessment of knowledge, attitude and practice of pharmacovigilance among the undergraduate medical students in a northern Indian tertiary care teaching hospital - an observational study. Int J Pharm Sci Res. 2017; 8(6): 2654-59.

Khan S, Goyal C, Chandel N, Rafi M. Knowledge, attitudes, and practice of doctors to adverse drug reaction reporting in a teaching hospital in India: An observational study. J Nat Sci Biol Med. 2013 Jan;4(1):191-6.

Muraraiah S, Rajarathna K, Sreedhar D, Basavalingu D, C R J. A questionnaire study to assess the knowledge, attitude and practice of Pharmacovigilance in a paediatric tertiary care centre. $J$ Chem Pharm Res. 2011, 3(6):416-422

Othman G, Ibrahim M, Alshakka M, Ansari M, Al-Qadasi F, Halboup A. Knowledge and Perception about Pharmacovigilance among Pharmacy Students of Universities in Sana'a Yemen. J Clin Diagn Res. 2017; 11(6): FC09-FC13

P V Chronicle PV Jobs \& Updates. [cited 12. 8. 18]. Available from: https://pvchronicle.com.

Shanko H, Abdela J. Knowledge, Attitudes, and Practices of Health Care Professionals Toward Adverse Drug Reaction Reporting in Hiwot Fana Specialized University Hospital, Harar, Eastern Ethiopia: A Crosssectional Study. Hosp Pharm. 2018;53(3):177-187

Suyagh M, Farah D, Abu Farha R. Pharmacist's knowledge, practice and attitudes toward pharmacovigilance and adverse drug reactions reporting process. Saudi Pharm J. 2015; 23(2): 147-153.

Vora M, Paliwal N, Doshi V, Barvaliya M, Tripathi C, 2012. Knowledge of adverse drug reactions and pharmacovigilance activity among the undergraduate medical students of gujarat. Int J Pharm Sci Res. 2012; 3(5): 1511-1515

\section{Tables}

Table-1:Gender wise comparison of mean scores for Knowledge, Attitude and Practice questions 


\begin{tabular}{|l|r|r|r|r|r|r|}
\hline \multicolumn{1}{|c|}{ Table-1: Gender wise comparison of mean scores for the following parameters } \\
\hline & Knowledge questions & Attitude questions & \multicolumn{2}{|c|}{ Practice questions } \\
\hline & 6.2 & 5.79 & 5.22 & 4.64 & 3.21 & 3.03 \\
\hline Mean & 2.1 & 2.25 & 1.78 & 1.8 & 1.47 & 1.47 \\
\hline Std. Deviation & 0.132 & 0.26 & 0.112 & 0.208 & 0.092 & 0.17 \\
\hline Std. Error & 5.95 & 5.27 & 5.04 & 4.29 & 3.06 & 2.74 \\
\hline Lower 95\% CI & 6.46 & 6.3 & 5.41 & 4.99 & 3.36 & 3.31 \\
\hline Upper 95\% CI & \multicolumn{7}{|c|}{} & & & & & & & \\
\hline
\end{tabular}

Table-2: Comparison of mean scores for Knowledge questions across different Levels of students

\begin{tabular}{|c|c|c|c|c|c|}
\hline & & & & & \\
\hline \multicolumn{6}{|l|}{ One-way analysis of variance } \\
\hline $\mathrm{P}$ value & $<0.0001$ & & & & \\
\hline $\mathrm{P}$ value summary & $* * *$ & & & & \\
\hline Are means signif. different? $(\mathrm{P}<0.05)$ & Yes & & & & \\
\hline Number of groups & 5 & & & & \\
\hline $\mathrm{F}$ & 36 & & & & \\
\hline R squared & 0.305 & & & & \\
\hline \multicolumn{6}{|l|}{ Bartlett's test for equal variances } \\
\hline Bartlett's statistic (corrected) & 16.3 & & & & \\
\hline $\mathrm{P}$ value & 0.0026 & & & & \\
\hline $\mathrm{P}$ value summary & $* *$ & & & & \\
\hline $\begin{array}{l}\text { Do the variances differ signif. ( } \mathrm{P}< \\
0.05 \text { ) }\end{array}$ & Yes & & & & \\
\hline ANOVA Table & SS & $\mathrm{df}$ & MS & & \\
\hline Treatment (between columns) & 598 & 4 & 149 & & \\
\hline Residual (within columns) & 1360 & 328 & 4.16 & & \\
\hline Total & 1960 & 332 & & & \\
\hline $\begin{array}{l}\text { Bonferroni's Multiple Comparison } \\
\text { Test }\end{array}$ & $\begin{array}{l}\text { Mean } \\
\text { Diff. }\end{array}$ & $\mathrm{t}$ & $\begin{array}{l}\text { Significant? } \mathrm{P}< \\
0.05 ?\end{array}$ & Summary & $95 \%$ CI of diff \\
\hline Level 7 vs Level 8 & -2.34 & 6.54 & Yes & $* * *$ & -3.35 to -1.33 \\
\hline Level 7 vs Level 9 & -3.36 & 9.27 & Yes & $* * *$ & -4.38 to -2.33 \\
\hline Level 7 vs Level 10 & -3.16 & 9.32 & Yes & $* * *$ & -4.12 to -2.20 \\
\hline Level 7 vs In Training & -3.39 & 10.2 & Yes & $* * *$ & -4.33 to -2.46 \\
\hline Level 8 vs Level 9 & -1.01 & 2.63 & No & ns & $\begin{array}{l}-2.10 \text { to } \\
0.0756 \\
\end{array}$ \\
\hline Level 8 vs Level 10 & -0.817 & 2.25 & No & ns & -1.85 to 0.211 \\
\hline Level 8 vs In Training & -1.05 & 2.95 & Yes & $*$ & $\begin{array}{l}-2.06 \text { to } \\
-0.0431 \\
\end{array}$ \\
\hline Level 9 vs Level 10 & 0.196 & 0.534 & No & ns & -0.842 to 1.23 \\
\hline Level 9 vs In Training & -0.0392 & 0.109 & No & ns & -1.06 to 0.981 \\
\hline Level 10 vs In Training & -0.235 & 0.697 & No & ns & -1.19 to 0.719 \\
\hline
\end{tabular}


Table-3: Comparison of mean scores for Attitude questions across different Levels of students

\begin{tabular}{|c|c|c|c|c|c|}
\hline \multicolumn{6}{|l|}{ One-way analysis of variance } \\
\hline $\mathrm{P}$ value & 0.0002 & & & & \\
\hline $\mathrm{P}$ value summary & *** & & & & \\
\hline $\begin{array}{l}\text { Are means signif. different? }(\mathrm{P}< \\
0.05)\end{array}$ & Yes & & & & \\
\hline Number of groups & 5 & & & & \\
\hline $\mathrm{F}$ & 5.82 & & & & \\
\hline R squared & 0.0668 & & & & \\
\hline \multicolumn{6}{|l|}{ Bartlett's test for equal variances } \\
\hline Bartlett's statistic (corrected) & 3.54 & & & & \\
\hline $\mathrm{P}$ value & 0.4716 & & & & \\
\hline $\mathrm{P}$ value summary & ns & & & & \\
\hline $\begin{array}{l}\text { Do the variances differ signif. ( } \mathrm{P}< \\
0.05)\end{array}$ & No & & & & \\
\hline ANOVA Table & SS & $\overline{d f}$ & MS & & \\
\hline Treatment (between columns) & 70.8 & 4 & 17.7 & & \\
\hline Residual (within columns) & 990 & 325 & 3.04 & & \\
\hline Total & 1060 & 329 & & & \\
\hline $\begin{array}{l}\text { Bonferroni's Multiple Comparison } \\
\text { Test }\end{array}$ & $\begin{array}{l}\text { Mean } \\
\text { Diff. }\end{array}$ & $\mathrm{t}$ & $\begin{array}{l}\text { Significant? } \mathrm{P}< \\
0.05 \text { ? }\end{array}$ & Summary & $\begin{array}{l}\text { 95\% CI of } \\
\text { diff }\end{array}$ \\
\hline Level 7 vs Level 8 & 1.12 & 3.62 & Yes & $* *$ & 0.245 to 1.99 \\
\hline Level 7 vs Level 9 & -0.34 & 1.09 & No & ns & $\begin{array}{l}-1.22 \text { to } \\
0.543\end{array}$ \\
\hline Level 7 vs Level 10 & 0.263 & 0.9 & No & ns & $\begin{array}{l}-0.564 \text { to } \\
1.09\end{array}$ \\
\hline Level 7 vs In Training & -0.0117 & 0.0408 & No & ns & $\begin{array}{l}-0.823 \text { to } \\
0.799\end{array}$ \\
\hline Level 8 vs Level 9 & -1.46 & 4.43 & Yes & $* * *$ & $\begin{array}{l}-2.39 \text { to } \\
-0.528\end{array}$ \\
\hline Level 8 vs Level 10 & -0.856 & 2.75 & No & ns & $\begin{array}{l}-1.74 \text { to } \\
0.0235 \\
\end{array}$ \\
\hline Level 8 vs In Training & -1.13 & 3.7 & Yes & $* *$ & $\begin{array}{l}-2.00 \text { to } \\
-0.267 \\
\end{array}$ \\
\hline Level 9 vs Level 10 & 0.604 & 1.92 & No & ns & $\begin{array}{l}-0.285 \text { to } \\
1.49\end{array}$ \\
\hline Level 9 vs In Training & 0.329 & 1.06 & No & ns & $\begin{array}{l}-0.544 \text { to } \\
1.20\end{array}$ \\
\hline Level 10 vs In Training & -0.275 & 0.952 & No & ns & $\begin{array}{l}-1.09 \text { to } \\
0.542\end{array}$ \\
\hline
\end{tabular}

Table-4: Comparison of mean scores for Practice questions across different Levels of students 
Table-4-Comparison of mean scores for Practice questions across different Levels of students

\begin{tabular}{|c|c|c|c|c|c|}
\hline \multicolumn{6}{|l|}{ One-way analysis of variance } \\
\hline $\mathrm{P}$ value & 0.4108 & & & & \\
\hline $\mathrm{P}$ value summary & ns & & & & \\
\hline Are means signif. different? $(\mathrm{P}<0.05)$ & No & & & & \\
\hline Number of groups & 5 & & & & \\
\hline F & 0.994 & & & & \\
\hline R squared & 0.0121 & & & & \\
\hline \multicolumn{6}{|l|}{ Bartlett's test for equal variances } \\
\hline Bartlett's statistic (corrected) & 3.21 & & & & \\
\hline $\mathrm{P}$ value & 0.5233 & & & & \\
\hline$P$ value summary & ns & & & & \\
\hline $\begin{array}{l}\text { Do the variances differ signif. ( } \mathrm{P}< \\
0.05 \text { ) }\end{array}$ & No & & & & \\
\hline ANOVA Table & SS & $\mathrm{df}$ & MS & & \\
\hline Treatment (between columns) & 8.53 & 4 & 2.13 & & \\
\hline Residual (within columns) & 697 & 325 & 2.15 & & \\
\hline Total & 706 & 329 & & & \\
\hline $\begin{array}{l}\text { Bonferroni's Multiple Comparison } \\
\text { Test }\end{array}$ & $\begin{array}{l}\text { Mean } \\
\text { Diff. }\end{array}$ & $\mathrm{t}$ & $\begin{array}{l}\text { Significant? } \mathrm{P}< \\
0.05 \text { ? }\end{array}$ & Summary & $95 \%$ CI of diff \\
\hline Level 7 vs Level 8 & -0.26 & 0.999 & No & ns & $\begin{array}{l}-0.993 \text { to } \\
0.474\end{array}$ \\
\hline Level 7 vs Level 9 & -0.0503 & 0.192 & No & ns & $\begin{array}{l}-0.792 \text { to } \\
0.691\end{array}$ \\
\hline Level 7 vs Level 10 & -0.442 & 1.8 & No & ns & -1.14 to 0.252 \\
\hline Level 7 vs In Training & -0.145 & 0.604 & No & ns & $\begin{array}{l}-0.826 \text { to } \\
0.535\end{array}$ \\
\hline Level 8 vs Level 9 & 0.209 & 0.756 & No & $\mathrm{ns}$ & $\begin{array}{l}-0.573 \text { to } \\
0.992\end{array}$ \\
\hline Level 8 vs Level 10 & -0.183 & 0.7 & No & ns & $\begin{array}{l}-0.922 \text { to } \\
0.556\end{array}$ \\
\hline Level 8 vs In Training & 0.114 & 0.444 & No & ns & $\begin{array}{l}-0.611 \text { to } \\
0.839\end{array}$ \\
\hline Level 9 vs Level 10 & -0.392 & 1.49 & No & ns & -1.14 to 0.354 \\
\hline Level 9 vs In Training & -0.0952 & 0.367 & No & ns & $\begin{array}{l}-0.828 \text { to } \\
0.638\end{array}$ \\
\hline Level 10 vs In Training & 0.297 & 1.22 & No & ns & $\begin{array}{l}-0.389 \text { to } \\
0.983\end{array}$ \\
\hline
\end{tabular}

\section{Supplementary Files}

This is a list of supplementary files associated with this preprint. Click to download.

- supplement1.docx 
- supplement2.docx

Page 13/13 